\title{
Application of IF Rough Set on Knowledge Towards Malaria of Rural Tribal Communities in Tripura
}

\author{
Chhaya Gangwal $^{1}$, R. N. Bhaumik ${ }^{2}$ and Shishir Kumar ${ }^{3}$ \\ ${ }^{1}$ Research Scholar, Tripura University \\ c_hhaya@hotmail.com \\ ${ }^{2}$ Emeritus Fellow (UGC) and Professor of Mathematics(Rtd.) \\ bhaumik_r_n@yahoo.co.in \\ ${ }^{3}$ Assistant Professor (Biostatistics), Department of Community Medicine, \\ Agartala Government Medical College, Agartala, Tripura \\ shishirpunia@gmail.com
}

\begin{abstract}
Handling uncertainty and impreciseness of knowledge appears to be a challenging task in Information Systems. Intuitionistic fuzzy (IF) set theory and rough set theory enhances databases by allowing it for the management of uncertainty and impreciseness. This paper presents a new efficient query optimization technique for the multi-valued or imprecise IF rough database. The usefulness of this technique was illustrated on malaria knowledge from the rural tribal communities of Tripura where most of the information is multi-valued and imprecise. Then the querying about knowledge on malaria is executed into SQL server to make the implementation of IF rough data querying simpler.
\end{abstract}

Keywords: Intuitionistic Fuzzy Set, Rough Set, Relational Database, IF Rough Relational Database

\section{Introduction}

Many real world applications and systems deal with imprecise, uncertain or multivalued data. For such systems, we need information management systems that provide support for managing this imprecise and uncertain data. Significant work has been done in incorporating uncertainty management in relational databases (RDBs) [3] using theories such as fuzzy set [10], rough set [9] and intuitionistic fuzzy (IF) set [1] to name a few. Each of the theories has some advantages in modeling some type of uncertainty over another.

At present, there are only a few researches on the theory architecture of IF and rough relational database. Currently, the study of rough data querying on simple select-querying are proposed by [7, 8] for multi-valued attributes, whereas, there are many research issues regarding the management of imprecise data in database environment. To manage impreciseness in relational databases IF set theory finding wide usefulness.

Recently [5], we presented an IF rough relational database model and described the IF rough SQL used for querying in IF rough databases and applied [6] this model on diabetic patient databases. In this paper a new efficient query optimization technique for the multi-valued or imprecise IF rough database on malaria knowledge from the rural tribal communities of Tripura is presented. This methodology is perceived by using encoding and normalizing techniques. 


\section{Preliminaries}

\subsection{Intuitionistic Fuzzy (IF) set [1]}

An IF set $A$ in a nonempty set $X$ is $A=\left\{\left(x, \mu_{A}(x), v_{A}(x)\right): x \in X\right\}$, where $\mu_{A}(x)$ and $v_{A}(x)$ are functions from $X$ to $I=[0,1]$ such that $0 \leq \mu_{A}(x)+v_{A}(x) \leq 1, \forall x \in X$. The numbers $\mu_{\mathrm{A}}(\mathrm{x})$ and $\nu_{\mathrm{A}}(\mathrm{x})$ represent the degree of membership and degree of non-membership for each element $x \in X$ to A respectively. The quantity $\pi_{A}(x)=1-\left(\mu_{A}(x)+v_{A}(x)\right)$ is called the degree of indeterminacy or hesitation of the element $\mathrm{x} \in \mathrm{X}$ to the IF set $\mathrm{A}$.

\subsection{Rough Set [9]}

Let $R$ be an indiscernibility relation on universal set $U$. The pair $S=(U, R)$ is called a Pawlak approximation space. Then for any non-empty subset $X$ of $U$, the sets $\underline{R} X=\left\{x \in U:[x]_{R} \subseteq X\right\}$ and $\bar{R} X=\left\{x \in U:[x]_{R} \cap X \neq \phi\right\}$ are respectively, called the lower and the upper approximations of $X$ in $S$. The set approximation $\underline{R} X,(U-\bar{R} X)$ and $(\bar{R} X-\underline{R} X)$ are described as $\mathrm{R}$-positive region, $\mathrm{R}$-negative region and $\mathrm{R}$-boundary region respectively, where $[\mathrm{x}]_{R}$ denotes the equivalence class of the relation $R$ containing the element $x . X$ is said to be definable set, if $\overline{R(X)}=\underline{R(X)}$. Otherwise $X$ is said to be rough set. Rough relational database [2] is a special kind of multi-valued information system S. Let $S=(\mathrm{U}, \mathrm{A}, \mathrm{D}, \mathrm{R}), \mathrm{U}$ is the set of all the tuples, A is the attribute set, D is the domains of attribute sets, and $R$ is the equivalence classes on the D. For any attribute $A_{i}$ $\in A, D_{A i}$ is the domain of $A_{i}, R_{A i}$ is the equivalence class of attribute $A_{i}$, a tuple $r \in U$, $r\left(A_{i}\right)$ is the tuple r's value on attribute $A_{i}$, and $r\left(A_{i}\right) \subseteq D_{A i}$.

\section{IF Rough Relational Database Model [5, 6]}

In this model, a tuple $t_{i}$ takes the form $\left(d_{i 1}, d_{i 2}, \ldots, d_{i m}, d_{i[\mu, v]}\right)$ where $d_{i j}$ is a domain value of a particular domain set $\mathrm{D}_{\mathrm{j}}$ and $\mathrm{d}_{\mathrm{i}[\mu, v]} \in[0,1]$, the domain for IF membership and nonmembership values denoted as $\mathrm{d}_{\mathrm{i}[\mu, v]}=\left[\mathrm{d}_{\mathrm{i \mu}}, \mathrm{d}_{\mathrm{iv}}\right]$. In the relational database, $\mathrm{d}_{\mathrm{ij}} \in \mathrm{D}_{\mathrm{j}}$. In the IF rough relational database except for the membership and non-membership values $\mathrm{d}_{\mathrm{ij}} \subseteq \mathrm{D}_{\mathrm{j}}$ where $\mathrm{d}_{\mathrm{ij}} \neq \phi$.

Definition 1 Let $P\left(D_{i}\right)$ be the power set of $D_{i}$. An IF rough relation $R$ is a subset of the product set $P\left(D_{1}\right) \times P\left(D_{2}\right) \times \ldots P\left(D_{m}\right) \times D_{[\mu, v]}$, where $D_{[\mu, v]}$ is the domain for membership and non-membership value of the closed interval $[0,1]$ and $P\left(D_{i}\right)=P\left(D_{i}\right)-\phi$.

Definition 2 Let $t_{i}=\left(d_{i 1}, d_{i 2}, \ldots, d_{i m}, d_{i[\mu, v]}\right)$ be an IF rough tuple. An interpretation of $t_{i}$ is a tuple $\alpha=\left(a_{1}, a_{2}, \ldots, a_{m, n}, a_{[\mu, v]}\right)$ where $a_{j} \in d_{i j}$ for each domain $D_{j}$.

\subsection{IF Rough Methodology}

Suppose the IF rough relation $\mathrm{R}$ and multi-valued or imprecise attribute $a \in \mathrm{A}, \mathrm{D}_{a}$ is attribute $a$ 's domain, $\mathrm{R}_{a}$ is attribute $a$ 's equivalence class and $\mathrm{D}_{[\mu, v]}$ is the domain for membership and non-membership value of the closed interval $[0,1]$.

Then, it can be noted that: $\mathrm{D}_{a} / \mathrm{R}_{a}=\left\{[\mathrm{x}]_{\mathrm{R} a} \mid \mathrm{x} \in \mathrm{D}_{a}\right\}=\left\{\mathrm{c}_{1}, \mathrm{c}_{2}, \ldots, \mathrm{c}_{\mathrm{k}}\right\}$, and $\mathrm{K}=\left|\mathrm{D}_{a} / \mathrm{R}_{a}\right|$. Let $\mathrm{v}$ be an arbitrary value of the multi valued attribute $a$ and ENCODE be a map function. ENCODE: ENCODE $(\mathrm{a}, \mathrm{v}) \rightarrow \mathrm{c}_{1}, \mathrm{c}_{2}, \ldots \mathrm{c}_{\mathrm{k}}$, where $\mathrm{v} \subseteq \mathrm{D}_{a}$. $\mathrm{c}_{\mathrm{i}}=1$ if $\mathrm{x} \in \mathrm{v} \wedge \mathrm{x} \in \mathrm{c}_{\mathrm{i}}$, otherwise $\mathrm{c}_{\mathrm{i}}$ $=0$ and for imprecise attribute $a$, removing all the imprecise attributes from the relation $\mathrm{R}$, 
create one separate table for each imprecise attribute, and put all attributes in the primary key with $\mathrm{D}_{[\mu, v]}$.

Based on the above methodology, we get the following algorithm.

\subsection{IF Rough Algorithm}

Let the select-condition be " $a=\mathrm{v}$ ", $a$ is an attribute and its domain is $\mathrm{D}_{a}$ and $a \_$code is the encoding filed of $a$ and $a_{\mu}$ and $a_{v}$ are the membership and non-membership values of $a$ and $\mathrm{v}$ is an arbitrary value, where $\mathrm{v} \subseteq \mathrm{D}_{\mathrm{a}}$.

1. Calculate the value of $a_{\mu}, a_{v}$ and $\operatorname{ENCODE}(a, v)$, and note the result as $c$, that is $\mathrm{c}=\operatorname{ENCODE}(\mathrm{a}, \mathrm{v})$ or $\mathrm{c}=\mathrm{a}_{\mu}, \mathrm{a}_{\mathrm{v}}$.

2. The search condition of certain data querying can be modified to

$$
\text { " a_code }=c \text { with } a_{\mu}=1 \text { and } a_{v}=0 " \text {. }
$$

The search condition of possible data querying can be modified to "a_code $\geq \mathrm{c} \wedge$ a_code and $\mathrm{c}=\mathrm{c}$ " with $\mathrm{a}_{\mu} \leq 1$ and $\mathrm{a}_{v} \geq 0$.

\section{Application: Knowledge towards Malaria}

Malaria is the world's most important tropical disease and kills more people than any other disease. It has been an important public health problem in Tripura too. One of the important reasons behind this is their poor knowledge about malaria. In this study we collected the data of knowledge towards malaria of rural tribal communities of Tripura and implemented efficient IF rough query optimization technique on malaria knowledge via SQL server.

For the study, a pre-structured and pre-tested questionnaire was prepared on malaria knowledge. 216 persons were selected from the rural tribal communities of Tripura. A proforma was filled up with the required information after a verbal interview of the family members who were above 18 years of age. Before the interview a consent form was also signed by the subjects. The consent was in written form and was in an understandable language of the subjects.

The collected information is divided into the following tables (i) Socio-demographic characteristics (ii) Knowledge about malaria. We have used IF rough methodology to convert the qualitative or quantitative data into encoding, membership and non-membership values and implemented into IF rough algorithms. The encoding technique is shown as below:

Suppose cause of malaria is the multi-valued attribute about knowledge of the study population towards malaria. The domain and equivalence class of attribute "cause_malaria" are $D_{\text {cause_malaria }}$ and $R_{\text {cause_malaria }}$. These are defined as follows:

$\mathbf{D}_{\text {cause_malaria }}=\{$ Mosquito, Malaria parasite, Bad personal hygiene, Insanitary conditions, Contaminated water, God given, Man made, Evil spirit, Don't know\}

$\mathbf{R}_{\text {cause_malaria }}=\{[$ Mosquito, Malaria parasite $][$ Bad personal hygiene, Insanitary conditions, Contaminated water] [God given, Man made, Evil spirit] [Don't know]\}

Now, for instance to encode the arbitrary value $(v)=\{$ Mosquito, Contaminated water $\}$ of the multi-valued attribute "cause_malaria", it is compared with each equivalence class of $\mathrm{R}_{\text {cause_malaria. }}$ Arbitrary value (v) exists for first two equivalence classes due to which the first two bits are 1 each, the remaining bits are 0. Therefore, the cause_malaria_code is 1100. (Appendix Table I) 


\subsection{Table Design}

In the logical design phase, Data Definition Language (DDL) command is used to design tables (relations). CREATE command is used to define the relations. Brief descriptions of the tables are as follows:

\section{SQL: CREATE TABLE STATEMENT}

The SQL CREATE TABLE statement is used to create and define a table.

\section{(1) CREATE TABLE SOCIO-DEMOGRAPHIC INFORMATION \\ (ID DECIMAL (3), \\ NAME $\quad$ CHAR (50), \\ SEX CHAR (25), \\ AGE DECIMAL (3), \\ COMMUNITY CHAR (30), \\ VILLAGE CHAR(30), \\ LITERACY CHAR (30), \\ MU $\quad \operatorname{CHAR}(10)$, \\ NMU CHAR (10), \\ PRIMARY KEY (ID));}

SOCIO-DEMOGRAPHIC INFORMATION: The socio-demographic table has attributes ID, name, sex, age, community, village, literacy, membership values (MU) and non-membership values (NMU).

\section{(2) CREATE TABLE KNOWLEDGE ABOUT MALARIA}

$\begin{array}{ll}\text { (ID } & \text { DECIMAL (3), } \\ \text { CAUSE OF MALARIA } & \text { CHAR (145), } \\ \text { CAUSE OF MALARIA_C } & \text { CHAR (5), } \\ \text { SYMPTOMS OF MALARIA } & \text { CHAR (145), } \\ \text { SYMPTOMS OF MALARIA_C } & \text { CHAR (5), } \\ \text { SEASON OF MALARIA } & \text { CHAR }(145), \\ \text { SEASON OF MALARIA_C } & \text { CHAR (5), } \\ \text { SPREAD DISEASE } & \text { CHAR (145), } \\ \text { SPREAD DISEASE_C } & \text { CHAR (5), } \\ \text { SOURCE OF KNOWLEDGE } & \text { CHAR (145), } \\ \text { SOURCE OF KNOWLEDGE_C CHAR (5), } \\ \text { PEOPLE COME TO KNOW ABOUT MALARIA CHAR (145), } \\ \text { PEOPLE COME TO KNOW ABOUT MALARIA_C CHAR (5), } \\ \text { FOREIGN KEY (ID)); }\end{array}$

KNOWLEDGE ABOUT MALARIA: This table shows knowledge of the study population towards malaria. The attributes are ID, cause of malaria, symptoms of malaria, commonest season of getting malaria, cause of spreading the disease, sources of knowledge regarding malaria and the methods by which the person come to know about malaria. Each attribute also contains the encoding of the respective attribute. 


\section{SQL: INSERT STATEMENT}

The SQL INSERT statement is used to insert the records into tables.

(1)

(2)

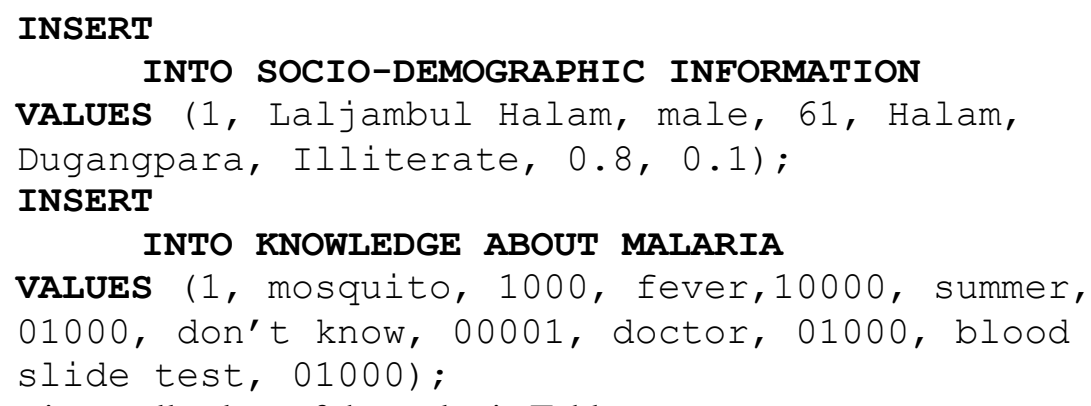

Similarly, we can insert all values of the tuples in Tables.

\section{SQL: IF ROUGH DATA QUERIES}

Once the tables were created and populated with data, we evaluated their utility with sample queries. The queries are divided into two parts: certain data query and possible data query. Certain data querying is that search there objects fully matching the querying conditions and the querying results are obtained by the lower approximation of attributes values. Possible data querying is rough querying and the querying results are obtained by the upper approximation of attributes values. The queries and their results are as follows:

Question 1: Select ID of those respondents who are males, age $\geq 40$, illiterate and know that mosquito as the cause of malaria followed by contaminated water.

\section{Certain Data Query:}

SELECT (Socio-demographic.ID), (Socio-demographic.age), (Sociodemographic.sex), (Socio-demographic.Liteacy), (Knowledge About Malaria.Cause malaria)

FROM Knowledge About Malaria, Socio-demographic

WHERE (lage $\geq 40$ ) and (sex ='male') and (Literacy ='illiterate') and ( $\mathrm{MU}=1)$ and (NMU $=0$ ) and (Cause of malaria_c = '1100')) and (Socio-demographic.ID = Knowledge About Mālaria.ID);

\section{Lower Approximation}

Result [Table 1(a): Knowledge about Cause of Malaria]

\begin{tabular}{|c|c|c|c|}
\hline ID & age $\operatorname{sex}$ & Literacy & Causemalaria \\
\hline 3 & 75 mal & Iliterate & mosquito, contaminatedwater \\
\hline 191 & $41 \mathrm{mal}$ & Illiterate & mosquito, contamimated water \\
\hline 207 & 70 màl & & mosquito, contaminated water \\
\hline
\end{tabular}




\section{Possible Data Query:}

SELECT (Socio-demographic.ID), (Socio-demographic .age)

, (Socio-demographic.sex), (Socio- demographic.

Literacy), (Knowledge About Malaria.Cause malaria)

FROM Knowledge About Malaria, Socio-demographic

WHERE ( $($ age $>=40)$ and (sex $={ }^{\prime}$ male') and (Literacy $=^{\prime}$ illiterate') and (MU $\left.\leq 1\right)$ and (NMU $\geq 0$ ) and (Cause of

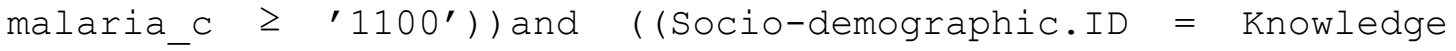
About Mālaria.ID)) ;

\section{Upper Approximation}

Results [Table 1(b): Knowledge about Cause of Malaria]

\begin{tabular}{|c|c|c|c|}
\hline ID & age sex & Literacy & Causemalaria \\
\hline 1 & 61 male & Iliterate & mosquito, contaminated water \\
\hline 1 & 62 male & Iliterate & mosquito, contaminated water \\
\hline 1 & 63 male & Illiterate & mosquito, contaminated water \\
\hline 3 & 75 male & Illiterate & mosquito, contaminated wates \\
\hline 191 & 41 mals & Illit & mosquito, contami mated water \\
\hline 7 & & & \\
\hline
\end{tabular}

Explanation: From Table 1(a), we get the results of certain data querying are $\{3,191,207\}$ and from Table 1(b), possible data querying are $\{1,3,191,207\}$.

Question 2: Retrieve ID and name of those respondents who are Chakma and above 30 years old and mentioned that doctors as their source of knowledge about malaria.

Query: SELECT (Socio-demographic .ID), ( Socio-demographic - Name), ( Socio-demographic. Community), (Socio-demographic. Age), ( Knowledge About Malaria .Source_of_Knowledge)

FROM Knowledge About Malaria, Socio-demographic WHERE ((Community ='Chakma') and (Age > 30) and (MU = 1) and $(\mathrm{NMU}=0)$ and (Knowledge About Malaria. Source of knowledge_c ='01000')) and ((Socio-demographic.ID= Knowledge About

Malaria.ID)); 


\section{Result [Table 2: Doctors is the Source of Knowledge about Malaria]}

\begin{tabular}{|c|c|c|c|c|}
\hline ID & Name & Community & Age & Source_of_Knowledge \\
\hline 82 & Gouranga Chakma & Chakma & 41 & Doctor \\
\hline 84 & Halog Chakma & Chakma & 50 & Doctor \\
\hline 90 & Sangita Chakma & Chakma & 35 & Doctor \\
\hline 92 & Tara Chakma & Chakma & 41 & Doctor \\
\hline 95 & Goraitien Chakma & Chakma & 35 & Doctor \\
\hline 97 & Lalnghaka Chakma & Chakma & 40 & Doctor \\
\hline 107 & Neisekbhum Chakma & Chakma & 65 & Doctor \\
\hline 136 & Lalnghaka Chakma & Chakma & 70 & Doctor \\
\hline 137 & Gouranga Chakma & Chakma & 38 & Doctor \\
\hline 142 & Satya Chakma & Chakma & 41 & Doctor \\
\hline 148 & Bideejoi Chakma & Chakma & 50 & Doctor \\
\hline 157 & Neisekbhum Chakma & Chakma & 70 & Doctor \\
\hline 159 & Goraitien Chakma & Chakma & 35 & Doctor \\
\hline 160 & Haidan Chakma & Chakma & 40 & Doctor \\
\hline
\end{tabular}

\section{Conclusion}

This paper deals with the information on knowledge of the tribal people towards malaria of Tripura and presented a new efficient query optimization technique for the multi-valued or imprecise IF rough database on malaria knowledge. Then the querying is executed into SQL server to make the implementation of IF rough data querying simpler. Finally, we see that our solution makes the implementation of IF rough data querying much simpler and more efficient and can serve in a better way the purpose of medical experts.

\section{References}

[1] K. Atanassov, "Intuitionistic Fuzzy Sets, Fuzzy Sets and Systems”, vol. 20, (1986), pp. 87-96.

[2] T. Beaubouef and F. E. Petry, "Uncertainty modeling for database design using intuitionistic and rough set theory", Jour. Intelligent and Fuzzy Systems, vol. 20, no. 3, (2009), pp. 105-117.

[3] E. F. Codd, "A relational model of data for large shared data banks", Comm. ACM, vol. 13, pp. 377-387, (1970).

[4] C. Gangwal and R. N. Bhaumik, "Normalization of Intuitionistic fuzzy rough relational Databases", IJARCET, vol. 1, no. 6, (2012), pp. 24-27.

[5] C. Gangwal and R. N. Bhaumik, "Intuitionistic fuzzy rough relational database model", International Journal of Database Theory and Application, vol. 5, no. 3, (2012), pp. 91-102.

[6] C. Gangwal, R. N. Bhaumik and S. Kumar, "Application of IF rough relational model to deal with Diabetic patients, Rough Sets, Fuzzy Sets, Data Mining, and Granular Computing”, Lecture Notes in Computer Science (LNCS), vol. 8170, (2013), pp. 191-199.

[7] S. Hiremath and P. Chandra, "Efficient approach for query optimization in rough data", Internat. J. of Sci and Research, vol. 2, no. 6, (2013), pp. 239-242.

[8] X. Hu, X. Hong and Y. Yuan, "A high efficiency approach to querying rough data", Fuzzy system and knowledge discovery, vol. 2, (2007), pp. 308-313.

[9] Z. Pawlak, "Rough sets", Internat. J. Comput. Inform. Sci, vol. 11, (1982), pp. 341-356.

[10] L. A. Zadeh, "Fuzzy sets", Information Control, vol. 18, (1965), pp. 338-353. 


\section{APPENDIX -}

\section{Table I - Encoding of Knowledge of the Study Population towards Malaria}

\begin{tabular}{|c|c|c|}
\hline Domain & Equivalence Class & Encoding \\
\hline Cause of malaria & & \\
\hline Mosquito & \multirow[t]{2}{*}{ [Mosquito, Malaria parasite] } & \multirow[t]{2}{*}{1000} \\
\hline Malaria parasite & & \\
\hline Bad personal hygiene & \multirow{3}{*}{$\begin{array}{l}\text { [Bad personal hygiene, } \\
\text { Insanitary conditions, } \\
\text { Contaminated water] }\end{array}$} & \multirow[t]{3}{*}{0100} \\
\hline Insanitary conditions & & \\
\hline Contaminated water & & \\
\hline God given & \multirow{3}{*}{$\begin{array}{l}\text { [God given, } \\
\text { Man made, Evil spirit] }\end{array}$} & \multirow[t]{3}{*}{0010} \\
\hline Man made & & \\
\hline Evil spirit & & \\
\hline Don’t know & [Don't know] & 0001 \\
\hline \multicolumn{3}{|l|}{ Symptoms of malaria } \\
\hline Fever & \multirow[t]{3}{*}{ [Fever, Chills, Rigors] } & \multirow[t]{3}{*}{10000} \\
\hline Chills & & \\
\hline Rigors & & \\
\hline Headache & \multirow{3}{*}{$\begin{array}{l}\text { [Headache, Joint pains, Body } \\
\text { aches] }\end{array}$} & \multirow[t]{3}{*}{01000} \\
\hline Joint pain & & \\
\hline Body ache & & \\
\hline Loss of Appetite & \multirow{5}{*}{$\begin{array}{l}\text { [Malaise, Nausea, Weakness, } \\
\text { Loss of appetite, Vomiting] }\end{array}$} & \multirow[t]{5}{*}{00100} \\
\hline Vomiting & & \\
\hline Malaise & & \\
\hline Nausea & & \\
\hline Weakness & & \\
\hline Unconsciousness & [Unconsciousness] & 00010 \\
\hline Don't know & [Don't know] & 00001 \\
\hline \multicolumn{3}{|l|}{$\begin{array}{l}\text { Commonest season of getting } \\
\text { malaria }\end{array}$} \\
\hline Winter & [Winter] & 10000 \\
\hline Summer & [Summer] & 01000 \\
\hline Rainy season & [Rainy season] & 00100 \\
\hline Change of season & \multirow{2}{*}{$\begin{array}{l}\begin{array}{l}\text { [Change of season, } \\
\text { seasons] }\end{array}\end{array}$} & \multirow[t]{2}{*}{00010} \\
\hline All seasons & & \\
\hline Don't know & [Don't know] & 00001 \\
\hline \multicolumn{3}{|l|}{ How does the disease spread } \\
\hline Through mosquito & [Through mosquito] & 10000 \\
\hline Houseflies & [Houseflies] & 01000 \\
\hline Drinking contaminated water & \multirow{2}{*}{$\begin{array}{l}\text { [Drinking contaminated } \\
\text { water, Eating } \\
\text { contaminated food] }\end{array}$} & \multirow[b]{2}{*}{00100} \\
\hline Eating contaminated food & & \\
\hline Coughing & \multirow[t]{2}{*}{ [Coughing, Sneezing] } & \multirow[t]{2}{*}{00010} \\
\hline Sneezing & & \\
\hline Don’t know & [Don’t know] & 00001 \\
\hline $\begin{array}{l}\text { How does the person come to } \\
\text { know whether he/she has } \\
\text { malaria }\end{array}$ & & \\
\hline Symptoms & [Symptoms] & 10000 \\
\hline Blood slide test & [Blood slide test] & 01000 \\
\hline Urine test & & \\
\hline
\end{tabular}




\begin{tabular}{|c|c|c|}
\hline Stool test & [Urine test, Stool test] & 00100 \\
\hline X-ray & [X-ray] & 00010 \\
\hline Don’t know & [Don't know] & 00001 \\
\hline \multicolumn{3}{|l|}{$\begin{array}{l}\text { Source of knowledge } \\
\text { regarding malaria }\end{array}$} \\
\hline Family members & [Family members] & 10000 \\
\hline Doctors & \multirow[t]{2}{*}{ [Doctors, Health centre] } & \multirow[b]{2}{*}{01000} \\
\hline Health centre & & \\
\hline Qualified private practitioner & \multirow{2}{*}{$\begin{array}{l}\text { [Qualified private } \\
\text { practitioner, Health worker] }\end{array}$} & \multirow[b]{2}{*}{00100} \\
\hline Health worker & & \\
\hline Newspaper & \multirow{4}{*}{$\begin{array}{l}\text { [Newspaper, } \\
\text { Radio, Poster] }\end{array}$} & \multirow{4}{*}{00010} \\
\hline Television & & \\
\hline Radio & & \\
\hline Poster & & \\
\hline Nothing & [Nothing] & 00001 \\
\hline
\end{tabular}


International Journal of Bio-Science and Bio-Technology Vol.6, No.5 (2014) 